\title{
Nutritional status and cancer
}

\author{
Raquel González Garza ${ }^{1}$ and Raquel Garza Guajardo ${ }^{2 *}$ \\ ${ }^{1}$ Facultad de Salud Pública y Nutrición, Universidad Autónoma de Nuevo León, Mexico \\ ${ }^{2}$ Facultad de Medicina y Hospital Universitario "Dr José E González" Universidad Autónoma de Nuevo León, Mexico
}

\section{Editorial}

Cancer, the treatments that accompany it and the symptoms that in turn generate, increase the risk of suffering energy-protein malnutrition in patients with this disease, which causes a great deteriotation of health status, increased complications, decreased tolerance of cancer treatment and the patient's quality of life. Among the prognostic factors such as the type of tumor, the stage of the disease and the general condition of the patient, involuntary weight loss is the potentially most sensitive factor to therapeutic intervention. All this leads to the inclusión of an nutritional intervention as a therapeutic tool involved in cancer treatment.

Diet and nutrition are important factors throghout all the life course in the promotion and sustain of good health. Nutritional factors are responsable for about 30 percent of cancers in more developed countries and about 20 percent in low income countries. According to the World Health Organization (2010) between 30-50\% cancers can currently be prevented by avoiding risk factors and implementing existing evidence-based prevention strategies. Among these evidencebased strategies are the 2012 American Cancer Society Guidelines for Cancer Prevention which have a strong correlation between increased adherence to diet recommendations and decreased cancer mortality. However, certain factors related to nutritional status have been shown to increase aggressiveness in some cancers, such as hyperglycemia and prostate cancer.

The factors that affect the nutritional status and the risk of malnutrition are the initial nutritional status, site and stage of the disease, as well as the treatment approach. Treatment approaches, such as surgery, chemotherapy and radiotherapy, may have a directo or indirect adverse effect on the nutritional status. The success of cáncer therapy is determined by the nutritional status of the patient before and during treatment, by affecting the patient's ability to tolerate the therapy.
Ingestion is hindered by symptoms with nutritional effects such as: anorexia, changes in taste and smell, mucositis, dysphagia, stomatitis, nausea, vomiting, diarrhea, constipation, malabsorption, pain, depression and anxiety. It is posible that pre-existing comorbidities also play a role in cáncer formation; for example: excessive consumption of alcoholic beverages (head and neck and liver cancer) and obesity (breast, kidney, digestive tract and prostate cáncer, among others), or increase the risk of malnutrition at the time of the initial clinical picture. Sometimes the tumor has systemic or local effects that modify the nutritional status; among them, hypermetabolism, malabsorption, dysmotility and obstructions.

In conclusión, the nutritional intervention in the cancer patient exposed to active treatment must be early and be part of the overall treatment, in order to reduce complications arising from treatments, improve the quality of life and avoid early death. This intervention must be carried out taking into account that adequate screening and nutritional status assessment have been carried out, without forgetting that the degree of risk of antineoplastic treatment will pay a fundamental role in the pathogenesis of the risk of malnutrition [1-6].

\section{References}

1. Cáceres-Lavernia H, Neninger-Vinageras E, Menéndez Alfonso Y, Barreto-Peníe J (2016) Intervención nutricional en el paciente con cáncer. Rev Cubana Med 55: 59-73.

2. Patel A, Pathak Y, Patel J, Sutariya V (2018) Role of nutritional factors in pathogenesis of cancer. Food Quality and Safety 2: 27-36.

3. World Health Organization (2010) International agency for research on cancer. https:// www.iarc.fr/.

4. American cancer society, 2012. https://www.cancer.org/.

5. Emenaker N, Vargas A (2018) Nutrition and cancer research: Resources for the nutritioner and dietetics practitioner. J Acad Nutr Diet 118: 550-554.

6. Garza-Guajardo R, Delgado-Enciso I, Melo-de-la-Garza A, Rodríguez-Sánchez-IP, García-Lavastida L, et al. (2016) High fasting glucose, but no metabolic syndrome, is associated with elevated histologic aggressiveness in Mexican prostate cancer patients. Int J Clin Exp Pathol 9: 11951-11957.
Copyright: (C2019 Garza-Guajardo R. This is an open-access article distributed under the terms of the Creative Commons Attribution License, which permits unrestricted use, distribution, and reproduction in any medium, provided the original author and source are credited.
${ }^{\star}$ Correspondence to: Raquel Garza Guajardo, Facultad de Medicina y Hospital Universitario “Dr. José E. González” Universidad Autónoma de Nuevo León, México, E-mail: rgguajardo@yahoo.com

Received: December 11, 2019; Accepted: December 19, 2019; Published: December 23, 2019 